\title{
Health care consumers' perspectives on pharmacist integration into private general practitioner clinics in Malaysia: a qualitative study
}

This article was published in the following Dove Press journal:

Patient Preference and Adherence

19 March 2015

Number of times this article has been viewed

Pui San Saw'

Lisa M Nissen ${ }^{2,3}$

Christopher Freeman ${ }^{2,4}$

Pei Se Wong ${ }^{3}$

Vivienne $\mathrm{Mak}^{5}$

'School of Postgraduate Studies and Research, International Medical University, Kuala Lumpur, Malaysia;

${ }^{2}$ School of Clinical Sciences, Queensland University Technology, Brisbane, QLD, Australia; ${ }^{3}$ School of Pharmacy, International Medical University, Kuala Lumpur, Malaysia; ${ }^{4}$ School of Pharmacy, University of Queensland, St Lucia, QLD, Australia; ${ }^{5}$ School of Pharmacy, Monash University Malaysia, Selangor, Malaysia

Correspondence: Vivienne Mak School of Pharmacy, Monash University Malaysia, Jalan Lagoon Selatan 47500, Bandar Sunway, Selangor Darul Ehsan, Malaysia

Email vivienne.mak@monash.edu
Background: Pharmacists are considered medication experts but are underutilized and exist mainly at the periphery of the Malaysian primary health care team. Private general practitioners (GPs) in Malaysia are granted rights under the Poison Act 1952 to prescribe and dispense medications at their primary care clinics. As most consumers obtain their medications from their GPs, community pharmacists' involvement in ensuring safe use of medicines is limited. The integration of a pharmacist into private GP clinics has the potential to contribute to quality use of medicines. This study aims to explore health care consumers' views on the integration of pharmacists within private GP clinics in Malaysia.

Methods: A purposive sample of health care consumers in Selangor and Kuala Lumpur, Malaysia, were invited to participate in focus groups and semi-structured interviews. Sessions were audio recorded and transcribed verbatim and thematically analyzed using NVivo 10.

Results: A total of 24 health care consumers participated in two focus groups and six semistructured interviews. Four major themes were identified: 1) pharmacists' role viewed mainly as supplying medications, 2) readiness to accept pharmacists in private GP clinics, 3) willingness to pay for pharmacy services, and 4) concerns about GPs' resistance to pharmacist integration. Consumers felt that a pharmacist integrated into a private GP clinic could offer potential benefits such as to provide trustworthy information on the use and potential side effects of medications and screening for medication misadventure. The potential increase in costs passed on to consumers and GPs' reluctance were perceived as barriers to integration.

Conclusion: This study provides insights into consumers' perspectives on the roles of pharmacists within private GP clinics in Malaysia. Consumers generally supported pharmacist integration into private primary health care clinics. However, for pharmacists to expand their capacity in providing integrated and collaborative primary care services to consumers, barriers to pharmacist integration need to be addressed.

Keywords: pharmacist integration, private clinic, general practitioners, health care consumer, Malaysia

\section{Background}

Malaysia's health care system is a two-tier system consisting of the public and private sector. The public health care system, funded fully by the government and financed mainly from public tax revenue, provides services through a network of tertiary care centers, general hospitals, district hospitals, and public health clinics. ${ }^{1}$ The private sector, which consists of private hospitals and general practitioner (GP) clinics, provides both curative and preventive health care services on a non-subsidized, fee-for-service basis and mainly caters for those who can afford to pay. ${ }^{1}$ 
Pharmacists in the Malaysian primary care setting are mainly located in government-owned public health clinics (known as "klinik kesihatan") and community pharmacies. Pharmacy practice in public health clinics and community pharmacies are very different. Pharmacists in the public health clinics possess complete control over the supply of medicines. ${ }^{2}$ Pharmacists in these public health clinics also enroll patients with chronic diseases such as diabetes in a Medication Therapy Adherence Clinic (MTAC) program. ${ }^{3}$ For example, the Diabetes Medication Therapy Adherence Clinic is a pharmacist managed clinic aimed at improving medication adherence and glycemic control in diabetic patients in order to prevent diabetes-related complications. The pharmacist undertakes a medication review for the patient, identifies pharmaceutical care issues, provides recommendations and solutions to drug related problems, educates the patient, and monitors the therapeutic outcome until the therapeutic goal is achieved. The patient is followed up at a monthly or two monthly intervals by the pharmacist. Other MTAC services are available depending on patient needs such as warfarin MTAC, asthma MTAC, and renal transplant MTAC. Community pharmacists, unlike their counterparts, operate under rigid conditions and are often underutilized. ${ }^{2}$ Fewer than two prescriptions a day are filled at community pharmacies in Malaysia ${ }^{4}$ as private GPs are granted rights under the Poison Act 1952 to prescribe and dispense medications at their clinics. The main reason for the general public to visit a community pharmacy in Malaysia is usually to purchase a particular prescription medication or over-the-counter products. ${ }^{4}$

With the present health care system in Malaysia, primary care exerts only a limited gatekeeper function since many consumers can bypass a referral from a GP and directly attend specialists in hospitals with an additional fee. ${ }^{1,5}$ Consumers may receive treatments at different clinics or hospitals. As consumer details are not often communicated between the attending health care professionals, medicationrelated problems may occur. More complicated medication regimens, the inability to properly recall the regimen, the greater number of physicians consulted regularly, and the greater number of preparations used are associated with an increased risk of hospitalization related to non-compliance. ${ }^{6}$ Failure to integrate comprehensive care to patients can lead to an excessive burden onto hospital services, with acute wards becoming overwhelmed. ${ }^{7}$ With better coordinated care and prevention of adverse events and complications, savings on treatment costs and resources can be realized. ${ }^{5}$

Findings from the "National survey on the use of medicines by Malaysian Consumers 2012" showed that 56\% of consumers consult a government doctor when experiencing any health problems while $28 \%$ consult a private doctor. ${ }^{8}$ The study also demonstrated that $43.5 \%$ of consumers still did not understand the proper use of their medicines, unaware of their trade name (50.2\%), and were not aware of common side effects $(35.8 \%){ }^{8}$ Health care consumer education and counseling is perhaps one of the neglected areas in the private medical practice in Malaysia. The reason for this is the unavailability of the pharmacist at the dispensing window. ${ }^{9}$ In Malaysia, physicians are allowed to operate a small dispensary within their clinic. Unfortunately, the person who dispenses the medicine is not a pharmacist and this can be another factor that results in poor communication. ${ }^{9}$ Consumers' understanding and level of satisfaction may be better if a pharmacist briefs them about the disease and counsel on the safe use of medicine.

Health care reform to improve efficiency, effectiveness, consumers' choice, and equity has become an increasingly important agenda for policy change in Malaysia. ${ }^{10}$ The concept of "1 Care," the proposed re-structuring of the health system, is discussed with emphasis on the reform in the primary health care delivery system. ${ }^{11}$ The reforms are aimed at addressing three main concerns on seamless integration of care especially for the management of chronic diseases, ensuring universal coverage, and responsiveness of the health system in the face of increasing consumer expectations and safety. ${ }^{11}$ Pharmacists are medication experts and are easily accessible hence they can potentially contribute to the reform objectives.

Previous studies have shown that GPs do not conduct medication reviews in all patients who present for repeat prescription. ${ }^{12-14}$ Collaborative medicines management services delivered by pharmacists and GPs have already been successful in identifying and resolving medication-related problems, improving patient outcomes, and optimizing drug use and costs. ${ }^{15-20}$ Such services include pharmacist-led medication reviews, where pharmacists assess medications, monitor disease progression, and provide recommendations to GPs on a medication management plan.

Internationally, health care reforms have led to initiatives in integrating non-dispensing pharmacists into primary health care teams. Some of the broader examples of successful collaboration are detailed below:

- Medicines review in New Zealand, ${ }^{21}$ Taiwan, ${ }^{22}$ the Netherlands, ${ }^{23}$ and Australia ${ }^{24}$ is a collaborative service between pharmacists, GPs, and occasionally with nurses. Remuneration for these services vary from none (eg, in New Zealand, due to pharmacies competing for dispensing fees as part of the medicines review, some are providing reviews for free $)^{25}$ to pharmacists receiving a consultation 
fee on completion (eg, Taiwan, the Netherlands). In Australia, remuneration is provided to both pharmacists and GPs who participate in specific medicines review programs such as Home Medicines Review and Residential Medication Management Review. ${ }^{24}$

- Enhanced and local services are provided by community pharmacists in the UK in addition to the traditional dispensing services. Examples of enhanced and local services include stop smoking schemes, supervised administration (of methadone for drug misusers), consumer group directions (for example to supply emergency hormones and nicotine replacement therapy), and minor ailment schemes. ${ }^{24}$ Other health care professionals use the pharmacy's premises and facilities to provide all of the Primary Care Trust's enhanced and local services. All enhanced and local services are paid for by the local Primary Care Trust. ${ }^{24}$ A study by Bradley et al looking at the outcomes of the enhanced and local service pilots found that colocating pharmacies and GP practices facilitated the integration of pharmacists into primary health care teams through the benefits of regular face-to-face contact. ${ }^{26}$

- Integrating family Medicine and Pharmacy to Advance primary Care Therapeutics (IMPACT) in Canada was an initiative by the Primary Healthcare Transition Fund to place pharmacists within primary health care teams and is receiving widespread acceptance both in Canada and internationally. ${ }^{27}$ The IMPACT project was a multisite demonstration involving seven pharmacists, 70 physicians, and up to 150,000 consumers in a 2 -year program. ${ }^{28}$ In the study, at least one drug-related problem was identified and assessed by the pharmacist in $93.8 \%$ consumers. ${ }^{28}$ The total number of adverse drug reactions or potential adverse drug reactions identified was 315 (7.9\% of all drug-related problems identified). ${ }^{28}$ Physicians noted many benefits to working with pharmacists such as having a colleague who provided reliable drug information, getting fresh perspectives, and increased clinical security. ${ }^{28}$ From 2006-2007, the province of Ontario provided significant support for the introduction of approximately 87 pharmacists working in approximately 62 family health teams. ${ }^{29}$

- Primary health care clinics/medical centers with a pharmacist were identified in countries such as New Zealand. For example, the "Integrated Family Health Centres" is a new program under the Government initiative "Better, Sooner, More Convenient Primary Healthcare" and looks to move GPs, nurses, pharmacists, and allied health professionals within (or linked in with) the same health center in order to enhance multidisciplinary care and cost reduction. ${ }^{30}$
Previous work has been done in Australia to describe the opinions of health care consumers toward pharmacist integration into the general practice environment. In the study by Freeman et al, the health care consumer group viewed medication review, medication counseling, health care consumer advocacy, providing medication profile print-outs, and prescribing (prescription renewal) as a positive role. ${ }^{31}$ Remuneration was viewed as a facilitator and barrier to the health care consumer group. The health care consumer group also identified that promotion of services provided by the pharmacist could help the facilitation into the general practice setting. Barriers to facilitation include physical space and GPs' reluctance. ${ }^{31}$

In a separate Australian study by Tan et al, interviews were conducted with consumers on their experiences with pharmacists within the Australian general practice clinics. The study found that participants appreciated the time spent with the practice pharmacist specifically discussing their medications, in comparison with their GP or community pharmacist who were often viewed as being too busy. ${ }^{32}$ Although consumers were generally receptive to seeing the practice pharmacist, some still preferred consulting their GP about their medicines. ${ }^{32}$

Integrating pharmacists into private GP clinics is a new approach to Malaysia. To date, no studies have explored the views of Malaysian health care consumers on pharmacist integration into private GP clinics. This study aimed to explore Malaysian consumers' views on the integration of pharmacists within private GP clinics in Malaysia.

\section{Ethics approval}

This study was approved by the International Medical University Joint-Committee (IMU-JC) of Research and Ethics Committee (IMU R 117/2013).

\section{Methods}

Qualitative methods were used since little is known about consumers' opinions on extended roles of pharmacists in a GP clinic setting. Exploratory techniques using focus groups and semi-structured interviews with health care consumers were employed. Semi-structured interviews were offered in addition to focus groups to provide participants a choice to participate at an agreeable time and place when focus group arrangements were not favorable.

\section{Sample and recruitment}

A combination of purposive, snowball, and convenience sampling was used to obtain a sample of health care consumers. In this study, health care consumers refer to individuals 
who use health care products (including prescription and non-prescription medicine, over-the-counter products, vitamins, and supplements) and services, either for themselves or another family member that they care for. Letters of invitation were disseminated through peak consumer associations for participant recruitment to participate in the focus group or semi-structured interview. Participants had to be Englishspeaking, aged 18 years or older, and able to give informed consent. This study was carried out with participants from different backgrounds and experiences to increase data credibility and prevent information bias. Interviews and analyses were performed in an iterative manner until no new themes emerged.

\section{Interview guide and validity}

An interview schedule (Table 1) was developed based on the discussions with representatives of peak professional organizations and a review of the literature. ${ }^{31,32}$ Seeding questions were provided under each topic to encourage participant engagement and examples of potential scenarios provided where necessary. The schedule was used to direct the focus groups and interviews. The face validity of the interview schedule was tested with one health care consumer. Immediately following the interview, the researcher (PSS) discussed any queries, concerns, or issues related to the questions with the participants. Queries were addressed and minor amendments made to the interview guide.

\section{Data collection}

Data were collected between September 2013 and December 2013. All interviews and focus groups were conducted in a private discussion room or meeting room of the researcher's
(PSS) university. Immediately prior to each focus group/ semi-structured interview, participants were asked to complete a short (anonymous) demographic questionnaire to provide basic background of the participants. Written and verbal consent was obtained from all participants prior to the focus groups and interviews. All interviews were conducted according to participant preference at a mutually convenient place and time and facilitated by PSS. Throughout the focus groups and interviews, field notes were taken by PSS to capture key points, follow-up questions, and non-verbal activities from participants. The semi-structured interviews, focus group discussions, and field notes served to triangulate the data. Recruitment and interviews continued until data saturation was collectively reached, ie, where new information discovered does not add necessary points to the overall theory or framework. ${ }^{33}$ Focus groups and interviews were audio-recorded and transcribed verbatim (PSS and VM).

\section{Data analysis}

Data management was facilitated using NVivo 10 software (QSR International, Melbourne, VIC, Australia) to ensure systematic analysis of data. Units of information were identified and coded to represent an idea, opinion, or attitude. Themes were generated from the data set by making connections within and between participants using the general inductive approach. During the interpretation stage, investigators developed themes from reviews of all transcripts which offered possible explanations for what was happening within the data. This process was influenced both by the original study objectives and by new concepts generated inductively (consumers' experiences and views) from the data. The emergent themes were coded independently between two researchers

Table I Key topics covered in interview guide

Potential roles of integrated pharmacist in private GP clinic

a) What are your views on the services and care that you receive from private GP clinics?

b) What do you feel is the main role of pharmacists within our health care system?

c) What are your views and opinions on integrating a pharmacist into private GP clinics?

d) What roles would you see a pharmacist performing in a private GP clinic?

e) What roles would you not want to see a pharmacist performing in a private GP clinic?

f) Would you like to see a pharmacist in private GP clinics performing roles mentioned earlier?

Barriers to pharmacist integration into private GP clinic

a) What do you think are the barriers or challenges to have a pharmacist integrated into a private GP clinic?

Facilitators to pharmacist integration into private GP clinic

a) What do you think would facilitate or encourage pharmacist integration into private GP clinics

Benefits of pharmacist integration into private GP clinic

a) What do you think are the benefits of having a pharmacist to work together with the GPs within the private GP clinics

Remuneration to pharmacist

a) How do you think services provided by a pharmacist in private GP clinics should be funded?

Abbreviation: GP, general practitioner. 
(PSS and VM). Regular team meetings by the researchers facilitated critical exploration of participant responses, discussion of deviant cases, and agreement on recurring themes. Any discrepancies were resolved by discussion with the attempt to reach a consensus. All the quotes were screened and those that best captured the essence of the themes were extracted.

\section{Results}

A total of 24 health care consumers participated in two focus groups and six semi-structured interviews. Participants resided in areas within Selangor and Kuala Lumpur. Mean age ( \pm standard deviation) of the participants was $37.3( \pm 11.9)$ years, with a range of 24 years to 64 years. Demographic characteristics of participants are listed in Table 2 .

Four major themes emerged from the focus groups and semi-structured interviews and were supported by illustrative quotes from the participants $(\mathrm{C}=$ consumer $)$.

\section{Pharmacists' role viewed mainly as supply of medications}

Supply of medicines

Participants mainly viewed community pharmacists' role as suppliers of medicines and sale of over-the-counter medication, non-medicinal and beauty products.

Currently I think most of them are just over the counter selling medicine... and then those controlled medicine that need to go through a pharmacist, then we have to ask from them permission to sell it to us, that's what I feel. [C2]

In fact many of the community pharmacies except for the big ones, there are no pharmacists around [...] Because

Table 2 Demographic characteristics of participants

\begin{tabular}{ll}
\hline Characteristics & Total participants (n) \\
\hline Interview method & 24 \\
Focus group I & 7 \\
Focus group 2 & 11 \\
Semi-structured interviews & 6 \\
Sex & \\
Male & 7 \\
Female & 17 \\
Ethnicity & \\
Malay & 7 \\
Chinese & 12 \\
Indian & 5 \\
Highest level of education & \\
Secondary & 1 \\
College/university & 20 \\
Post-graduate & 3 \\
\hline
\end{tabular}

they sell a lot of other products [...] non medicinal type [...] like shampoo.

\section{Supply of medicines with consumer education}

Participants felt that pharmacists should provide information and education to consumers on the medicines supplied. Most participants envisage a good pharmacist to be able to assess and decide the best choice of treatment for consumers instead of merely supplying the medicine.

That's why the pharmacist role to advise the consumers on the effect, if it's really agreeable to you or not, the explanation must be there, the education.

I think a good pharmacist should not only take out the medicine and give to consumer. They should actually [...] when somebody like me, I go like can I get this specific antibiotic, they should actually say are you sure you want this or you know have you been taking this before, like do a check on the patient itself [...] So they should be more passionate about their job.

[C14]

Supply of health supplements with health promotion Some participants saw pharmacists as being helpful in promoting general health and wellness particularly in the aspects of diet and education on vitamins and food supplements.

Especially for supplements, we don't go and see doctors. If there's a pharmacist there then will be much better. Then we will get advice you see from the pharmacist.

We will approach the pharmacist as compared to the doctor. So that would be the opportunity and because we are going for healthy lifestyle so the pharmacist will play a more important role in that sense.

To guide not only your medication, you have to see that your food intake is also very important. So of course they [pharmacists] have to know little bit about diet on diabetic because a lot of them don't control their sugar you know, they just eat what they like.

[C3]

\section{Consumers' readiness to accept pharmacists in private GP clinics Difficulty in envisioning other roles of pharmacists besides the supply of medications}

Participants have difficulty envisioning other roles pharmacists can perform. Participants were not aware of what pharmacists are capable of doing in the private GP clinics besides dispensing medicines. They indicated that this was due to their exposure to pharmacy services only at hospitals and community pharmacies. 
I haven't really thought about that. But because our exposure to pharmacists is only at the hospitals and at the community pharmacy. So I don't know how you know the pharmacists can help.

I don't know because in my mind, the role of the pharmacist is to dispense the medicine.

Most participants did not know what areas pharmacists are trained in but generally felt that they could play an important role within the health care system. Participants agree that pharmacists should undergo continuous pharmacy skills and knowledge development to keep themselves updated with the latest medicine information.

And I believe that pharmacist can play a greater role you know in Malaysia rather than just giving medication.[C6]

They [pharmacists] are a waste of their talent. Most of them are just selling medicine. It's just like sales person. So it's a lot of wasted thing.

I think they [pharmacists] also like doctor, they should go for courses, upgrading themselves because I think in medication or in any medicine, you still have to keep up, keeping yourself up [...] Why not? Medicine you should.

[C3]

When given examples on potential extended pharmacist roles established overseas such as vaccine administration and medicine dosage adjustment, the participants gave split opinions on pharmacists performing such roles. Participants who supported these extended roles were confident with the clinical ability of Malaysian pharmacists to carry out such roles. However, other participants remained doubtful of Malaysian pharmacists and if they were capable of carrying out such activities effectively.

I think we should go ahead with it. Because you all are qualified pharmacist, you have gone through course, I think you all have, should have the right to help [...] to alter or to increase or to reduce because you all know better. [C3]

The quality of our pharmacist to some extent it's questionable here in Malaysia due to various factors and I would not be very comfortable if the doctor we has not been consulted if you are changing my dosage. So, yea I would split my view into two.

\section{Confidence and trust in pharmacists}

Almost all participants were not confident to have a nonpharmacist (often they are non-trained health professionals) dispensing medications currently at the private GP clinics.
They normally only employ people who are out from form 5 [referring to high school leavers] to be a so called clinical nurse, how much knowledge they have. I don't think they have that much knowledge.

[C3]

I don't know whether there is ethic issue or not to put the unqualified nurse in those health care [GP] clinics. I'm quite worry about that especially if you bring your kids right to those clinics.

Two participants mentioned that public health clinics and public hospitals have pharmacists to dispense medicines unlike non-pharmacists in private GP clinics.

In the public health clinic they have actually the pharmacist sitting there, is not a nurse right.

In hospitals the pharmacist explain. But in [GP] clinics normally they [non-pharmacist] don't explain. They just give you the medication and you take according to what they have told you.

[C4]

Participants felt dispensing medications in private GP clinics should be best carried out by a pharmacist to allow counter-checking of prescribed medicines and to provide advice on the side effects of medicines. Some participants also hoped pharmacists can check for appropriateness and necessity of the medications supplied. In doing so, all participants felt that pharmacists should have access to their medical records.

I don't think they [non-pharmacist in GP clinics] have that much knowledge. So I feel for dispensing the drugs it's better to have a pharmacist, a qualified pharmacist. [C3]

So it is actually good to have two different people doing it. Because there will be actually like a check and balance that sort of thing instead of one person diagnosing and prescribing.

[C11]

If the person dispensing the medicine to us can enlighten us and further on the side effects of the medicine and whether there are any other alternatives compared to what they have dispense and make us more knowledgeable then we can make a better choice.

$[\mathrm{C} 12]$

And then you know you go to the GP they will prescribe all sort of unnecessary, sometimes you don't need it also they will prescribe for you, through my experience [...] So I feel you know it should be in a proper I mean as a clinic, private clinic especially, qualified pharmacist there.

I'm ok with that [accessing medical records]. Because they can keep track of our condition each time right. So I think this is their responsibility also.

$[\mathrm{C} 1]$ 
Most participants agreed that pharmacists integrated into private GP clinics will spend more time discussing medicinerelated issues with the consumers because GPs are more often too busy to do so.

The pharmacist will spend more time with the patient to explain things. So if you [pharmacist] are able to explain to them [consumers] and tell them you know, the importance of taking the medication on a timely basis, why they must stick [to it], that will be better.

Sometimes doctors are too busy. They cannot like go through every detail with you. Will they spend half an hour with you? No way! Pharmacist can help out in that way you know.

[C3]

Some participants revealed that they have trust issues with pharmacists adopting additional clinical roles without consulting GPs first. Participants were unsure of the pharmacists' qualification and level of knowledge.

The quality of our pharmacist to some extent it's questionable here in Malaysia. I would not be very comfortable if the doctor we has not been consulted if you are changing my dosage.

All participants revealed that Malaysian consumers are generally very doctor-centered in seeking medical treatment and health advice. Participants strongly felt that public education and awareness on the roles of pharmacists is important.

Because the mentality is already there that means if you are sick you need to go to doctor. Doctor is the one giving you medicine. It's all been 50, 60, 100 years.

I think for a start is the role, the role of the pharmacist. How the pharmacist can actually help us? Yea, to create an awareness because these days is that if we are actually sick we just go to GP. That's it you know.

[C11]

Overall, participants viewed potential benefits in pharmacist integration into private GP clinics and were generally comfortable with the concept.

Pharmacist really know a lot of medications, what we should be given, not to be given, age limits for toddlers. Over the counter they can see the patient, at least they can interact. So when the pharmacist inside this private health care clinic, it will be safer to consumers.

I would say that it's the role of the pharmacist, if it's well regulated and to be actually assured of the quality of the services, yes then go ahead and have them integrated. [C11]
Participants felt that a higher salary, additional work benefits, and an improved public awareness toward the roles of pharmacists in Malaysia can facilitate pharmacist integration into private GP clinics.

I think it's the salary. Must be higher. It depends on the benefit.

So for a start, perhaps you should consider creating the awareness. What is the, how pharmacist can actually help, perhaps even better. What is the role of the pharmacist as compared to the physician? How best that you can do to help, to have a, to be healthy.

\section{Consumers' willingness to pay for pharmacy services}

Participants were concerned that the total cost of the treatment may increase and be passed on to consumers. Majority did not want to bear an extra cost of treatment.

Right now we don't pay any services for the pharmacy. If I think they want to charge for fees, I will not pay for that because we pay the doctors, now we have to pay the pharmacists.

[C2]

Some participants indicated that they are willing to pay for the service, ranging from RM 10-50 depending on the type of services offered by the pharmacist. Only a few participants were very willing to pay extra for pharmacy services.

I mean of course you must first show that you are capable of giving these kind of service to people, like we said, build up the confidence. People also will pay willingly and then pharmacist also get their pay.

$[\mathrm{C} 15]$

Participants felt that the government should provide some form of support or subsidy to pharmacists to work in the GP clinic.

The government should actually fund them [pharmacists]. The government should play a role in, because this is health care. They are collecting taxes so they should have a portion of it for pharmacist and that portion should be given as a grant or as a yearly basis for the pharmacist to run their pharmacy. [C4]

\section{Concerns about GPs' resistance to pharmacist integration}

All participants were concerned that a pharmacist in private GP clinics would encroach into the roles of GPs and impinge into GPs' income. They agreed this would result in GPs' resistance to pharmacist integration. 
Right now the GP are dispensing the medicine, so if you put somebody there, so I think they will not like it. [C2]

And to actually taking over a small portion of GPs' rice bowl. So that is also a hurdle you know. So how are you going to convince and persuade. Aside from the profit you are actually removing some functions away from them. How are you going to do that?

[C11]

Participants also felt that integrating a pharmacist into private GP clinics would incur more cost to the GPs. They felt that GPs in the rural areas may face difficulty to operate under such set-up.

Wait, I'm sure the doctors won't like it cause they will cough out more money to pay [the] pharmacist? [C14]

You may also face problem in rural areas. I would think places like east coast, east Malaysia [to face the same problem].

I do not see how a private clinic is going to employ a pharmacist. Because I think it is expensive. They not only just to, you know, to provide a service but the same time they also earning income you see. So if they employ a pharmacist it will be kind of financially burdened to them in that sense.

Putting cost issues aside, all participants strongly felt that GPs and pharmacists should work together toward better patient care. Participants understood that GPs and pharmacists have separate roles which would complement one another and contribute toward providing a comprehensive patient care, ie, GPs responsible for diagnosis and treatment and pharmacists as medicine experts.

I think it's a duty of care, a split of duty of care between these two very important roles.

It will be good to us if we too have that kind of integration. That mean we leave to the expert for doctor the expert is to know the disease, then for pharmacist the expert is to give the correct medicine according to the symptom

[C10]

\section{Discussion}

Our results indicate that participants were generally supportive of integrating a pharmacist into a GP clinic. Participants strongly agreed that dispensing medications in private GP clinics should be carried out by registered pharmacists. In doing so, pharmacists are able to screen for medication errors, drug-drug interactions, and engaging with consumers for further medication-related enquiries. This corresponds to previous studies on medication-related needs of consumers who expressed their main concerns in medication adverse effects. ${ }^{34,35}$ Therefore, a pharmacist integrated into a GP clinic can help to alleviate the medication-related concerns of health care consumers.

Although participants acknowledged pharmacists as medication experts, they indicated greater support for nonmedication-related roles such as "healthy living" advice. This is also described in a pilot study on the proposed new roles of community pharmacists in the $\mathrm{UK} .^{36}$

When given examples of other potential roles of pharmacists beyond dispensing in the GP clinics such as medication dosage adjustment and vaccination, participants had difficulty envisioning the expanded activities pharmacists are capable of undertaking. These reservations may stem from the limited interactions many participants have with pharmacists in community pharmacies. Similarly in a study by Freeman et al when participants were asked to discuss what roles they would perceive a pharmacist undertaking within a general practice setting, their responses resembled services already offered by pharmacists externally. ${ }^{31}$ A pilot study in the UK by Iversen et al also showed that consumers of pharmacy services may not be entirely supportive of the expanding role of the pharmacist, probably due to the lack of understanding of pharmacists' expertise. ${ }^{36}$ The results of this study also suggested that engagement of pharmacists in health improvement activities tend to be passive and productorientated. Literature also indicates that pharmacists tend to take a reactive rather than proactive approach to health promotion activity. ${ }^{37}$

There were issues surrounding the degree of involvement a pharmacist should have with consumers. Participants' response to the role of pharmacists appeared at times to be contradictory. When asked in a theoretical way about whether they perceive the pharmacist as medication expert able to adopt more clinical roles, participants' response tends to be cautious, suggesting that consumers generally have low expectations toward the role of pharmacists. Some participants are undoubtedly willing to take up the advice and services offered by a pharmacist, and it appears that they are regular clients who obtain their medicines from pharmacists. Similarly in a study by Gidman et a ${ }^{38}$ consumers were often reluctant to trust pharmacists to deliver unfamiliar services, particularly consumers with long-standing health conditions were perceived to be at "high risk" and preferred a GP-led service at all times.

It was apparent that participants were concerned with GPs' perceptions in the introduction of a new member into the private general practice. Some participants felt GPs 
may feel threatened by this new role, an opinion shared by GPs in international studies. ${ }^{39,40}$ On the contrary, previous studies conducted have found that prescribers welcomed new extended roles of practicing pharmacists as counselors and drug information providers, especially in developed nations. ${ }^{31,41,42}$ Due to differing health care systems and funding models, input from other key stakeholders especially GPs and pharmacists is critical. Nevertheless, consumers felt that multidisciplinary collaboration between GPs and pharmacists is vital for the betterment of patient care. Some participants suggested the need for multidisciplinary education and development of collaborative working relationships.

This study found no commonly agreed reimbursement structure. Most participants responded that the fee-for-service model would further increase health care cost to consumers. Unlike the GPs' consultation fee which is governed by the Schedule of Fees in Malaysia, the participants were not able to quantify an amount to pay for pharmacist services because they cannot visualize the services to be provided and the outcome of the service provision. In many instances, pharmacists are not compensated for health promotion or disease prevention and management activities. ${ }^{43}$ The majority of participants considered pharmacists to be both business people and health care professionals and these views are supported by a study carried out by Hargie et al in the UK. ${ }^{44}$ The participants urged Malaysian pharmacists and the Malaysian Pharmaceutical Society to undertake ethical responsibilities toward their consumers and adopt a more patient-oriented approach.

Overall findings showed that the participants' felt barriers to pharmacist integration into private GP clinics include GPs' resistance and potential increase in health care cost to consumers. To overcome these barriers, some participants felt that pharmacists need to portray credibility and competence. Government support to fund pharmacists in private GP clinics was seen as the major facilitator, with practices that embrace a multidisciplinary approach perceived as being more accommodating of pharmacist integration into private GP clinics.

The findings from this study will be useful to health care policy makers and could influence changes in the way pharmacists practice. The interpretation of the results may be limited by the confined area the participants were recruited from. The convenience nature of the sample has the potential to positively bias the results. However, as a general rule primary health care policy and practice is uniform nationwide. To reduce interviewer bias, seeding questions common to all the focus groups and semi-structured interviews were used to facilitate discussion. Being a qualitative study, the findings of this study cannot be generalized to all consumers in Malaysia. This study however helps to guide and develop future studies within the area.

\section{Conclusion}

Consumers generally supported pharmacist integration into private GP clinics. However, for pharmacists to expand their capacity in providing integrated and collaborative primary care services to consumers, barriers to pharmacist integration need to be addressed. Future research should further explore the methods of collaboration and trial their implementation.

\section{Acknowledgments}

This study was funded by the Exploratory Research Grant Scheme (ERGS) from the Ministry of Education (MOE) Malaysia under the grant number ERGS/1/2013/SKK02/ IMU/03/2. The authors would like to thank all participants for their contribution to this study.

\section{Author contributions}

PSS contributed to the data collection, data analysis, and writing of the paper. CF and LN contributed to the study design, writing of the paper, and provided guidance. PSW contributed to the study design, data collection, and writing of the paper. VM contributed to the study design, data collection, data analysis, writing of the paper, and guidance. All authors read and approved the final version of the manuscript.

\section{Disclosure}

The authors report no conflicts of interest in this work.

\section{References}

1. Jaafar S, Mohd Noh K, Abdul Muttalib K, Othman N, Healy J. Malaysia Health System Review. Health Systems in Transition. 2013;3(1).

2. Wong S. Pharmacy practice in Malaysia. Malaysian Journal of Pharmacy. 2001;(1):2-8.

3. Lim PC, Lim K. Evaluation of a pharmacist-managed diabetes medication therapy adherence clinic. Pharm Pract (Granada). 2010;8(4):250-254.

4. Chua SS, Lim KP, Lee HG. Utilisation of community pharmacists by the general public in Malaysia. Int J Pharm Pract. 2013;21(1):66-69.

5. Ministry of Health (MOH) Malaysia. Country Health Plan: 10th Malaysia Plan 2011-2015. Malaysia: Ministry of Health; 2010. Available from: http://www.moh.gov.my/images/gallery/Report/Country_health. pdf. Accessed December 29, 2014.

6. Malhotra S, Karan RS, Pandhi P, Jain S. Drug related medical emergencies in the elderly: role of adverse drug reactions and non-compliance. Postgrad Med J. 2001;77(913):703-707.

7. Forsyth DR, Chia YC. How should Malaysia respond to its ageing society? Med J Malaysia. 2009;64(1):46-50.

8. Pharmaceutical Services Division, Ministry of Health Malaysia. A National Survey on the Use of Medicines (NSUM) by Malaysian Consumers. Pharmaceutical Services Division, Ministry of Health Malaysia; 2012. Available from: http://www.pharmacy.gov.my/v2/sites/default/ files/document-upload/book.national-survey-use-medicines-2.12.pdf. Accessed December 28, 2014. 
9. Khan T, Hassali M, Al-Haddad M. Patient-physician Communication Barrier: A Pilot Study Evaluating Patient Experiences. J Young Pharm. 2011;3(3):250-255.

10. Merican MI, bin Yon R. Health care reform and changes: the Malaysia experience. Asia Pac J Public Health. 2002;14(1):17-22.

11. Mohamad Noh K. Primary health care reform in 1 Care for 1 Malaysia. International Journal of Public Health Research Special Issue. 2011:50-56.

12. Zermansky AG, Petty DR, Raynor DK, Freemantle N, Vail A, Lowe CJ. Randomised controlled trial of clinical medication review by a pharmacist of elderly patients receiving repeat prescriptions in general practice. BMJ. 2001;323(7325):1340-1343.

13. Zermansky AG, Petty DR, Raynor DK, Lowe CJ, Freemantle N, Vail A. Clinical medication review by a pharmacist of patients on repeat prescriptions in general practice: a randomised controlled trial. Health Technol Assess. 2002;6(20):1-86.

14. McGavock H, Wilson-Davis K, Connolly JP. Repeat prescribing management - a cause for concern? Br J Gen Pract. 1999;49(442): 343-347.

15. Tsuyuki RT, Johnson JA, Teo KK, et al. A randomized trial of the effect of community pharmacist intervention on cholesterol risk management: the Study of Cardiovascular Risk Intervention by Pharmacists (SCRIP). Arch Intern Med. 2002;162(10):1149-1155.

16. Carter BL, Ardery G, Dawson JD, et al. Physician and pharmacist collaboration to improve blood pressure control. Arch Intern Med. 2009; 169(21):1996-2002.

17. AlMazrouiNR, KamalMM, GhabashNM, YacoutTA, KolePL, McElnay JC. Influence of pharmaceutical care on health outcomes in patients with Type 2 diabetes mellitus. Br J Clin Pharmacol. 2009;67(5):547-557.

18. Krska J, Cromarty JA, Arris F, et al. Pharmacist-led medication review in patients over 65: a randomized, controlled trial in primary care. Age Ageing. 2001;30(3):205-211.

19. Stuijt CC, Franssen EJ, Egberts AC, Hudson SA. Appropriateness of prescribing among elderly patients in a Dutch residential home: observational study of outcomes after a pharmacist-led medication review. Drugs Aging. 2008;25(11):947-954.

20. Freeman C, Cottrell WN, Kyle G, Williams I, Nissen L. Does a primary care practice pharmacist improve the timeliness and completion of medication management reviews? Int J Pharm Pract. 2012;20(6): 395-401.

21. Sheridan J, Butler R, Brandt T, Harrison J, Jensen M, Shaw J. Patients' and pharmacists' perceptions of a pilot Medicines Use Review service in Auckland, New Zealand. Journal of Pharmaceutical Health Services Research. 2012;3(1):35-40.

22. Chan DC, Chen JH, Wen CJ, Chiu LS, Wu SC. Effectiveness of the medication safety review clinics for older adults prescribed multiple medications. J Formos Med Assoc. 2014;113(2):106-113.

23. van Mill JW. Pharmaceutical Care in Community Pharmacy: Practice and Research in the Netherlands. Ann Pharmacother. 2005;39(10): 1720-1725.

24. Pharmaceutical Society of Australia Ltd. Guidelines for pharmacists providing Residential Medication Management Review (RMMR) and Quality Use of Medicines (QUM) services. The Pharmaceutical Society of Australia; 2011. Available from: http://www.psa.org.au/download/ practice-guidelines/rmmr-and-qum-services.pdf. Accessed January 13, 2015.

25. Midland Community Pharmacy Group. Medicine Management Service in Community Pharmacy. Available from: http://www.midcpg.co.nz/ services/medicine-management-service. Accessed November 29, 2014.

26. Bradley F, Elvey R, Ashcroft DM, et al. The challenge of integrating community pharmacists into the primary health care team: a case study of local pharmaceutical services (LPS) pilots and interprofessional collaboration. J Interprof Care. 2008;22(4):387-398.
27. Management Committee. Moving Forward: Pharmacy Human Resources for the Future. Innovative Pharmacy Practices Volume II: Profiles of Pharmacy Practices. Ottawa: Canadian Pharmacists Association; 2008. Available from: http://blueprintforpharmacy.ca/docs/default-documentlibrary/2011/04/19/Innovative_Pharmacy_Practices_Volume_II_final. pdf?Status=Master. Accessed December 30, 2014.

28. Dolovich L, Pottie K, Kaczorowski J, et al. Integrating family medicine and pharmacy to advance primary care therapeutics. Clin Pharmacol Ther. 2008;83(6):913-917.

29. Management Committee. Moving Forward: Pharmacy Human Resources for the Future. Innovative Pharmacy Practices Volume I: Analysis and Overview. Ottawa: Canadian Pharmacists Association; 2008. Available from: http://blueprintforpharmacy.ca/docs/defaultdocument-library/2011/04/19/Innovative_Pharmacy_Practices_ Volume_I_final.pdf?Status=Master. Accessed December 30, 2014.

30. New Zealand Medical Association. Integrated Family Health Centres. New Zealand: NZMA; 2010. Available from: https://www.nzma. org.nz/_data/assets/pdf_file/0020/25517/Integrated-Family-HealthCentres-revised-July-2010.pdf. Accessed December 30, 2014.

31. Freeman C, Cottrell WN, Kyle G, Williams I, Nissen L. Integrating a pharmacist into the general practice environment: opinions of pharmacist's, general practitioner's, health care consumer's, and practice manager's. BMC Health Serv Res. 2012;12:229.

32. Tan EC, Stewart K, Elliott RA, George J. Stakeholder experiences with general practice pharmacist services: a qualitative study. BMJ Open. 2013;3(9):e003214.

33. Mason M. Sample Size and Saturation in PhD Studies Using Qualitative Interviews. Forum: Qualitative Social Research. 2010;11(3):1.

34. Bedell SE, Jabbour S, Goldberg R, et al. Discrepancies in the use of medications: their extent and predictors in an outpatient practice. Arch Intern Med. 2000;160(14):2129-2134.

35. Bislew HD, Sorensen TD. Use of focus groups as a tool to enhance a pharmaceutical care practice. J Am Pharm Assoc (2003). 2003; 43(3):424-433.

36. Iversen L, Mollison J, MacLeod TN. Attitudes of the general public to the expanding role of community pharmacists: a pilot study. Fam Pract. 2001;18(5):534-536.

37. Moore SM, Cairins CJ, Harding G, Craft M. Health promotion in community pharmacy. Int J Pharm Pract. 1996;4:109-116.

38. Gidman W, Ward P, McGregor L. Understanding public trust in services provided by community pharmacists relative to those provided by general practitioners: a qualitative study. BMJ Open. 2012;2(3) pii:e000939.

39. Edmunds J, Calnan MW. The reprofessionalisation of community pharmacy? An exploration of attitudes to extended roles for community pharmacists amongst pharmacists and General Practioners in the United Kingdom. Soc Sci Med. 2001;53(7):943-955.

40. Hughes CM, McCann S. Perceived interprofessional barriers between community pharmacists and general practitioners: a qualitative assessment. Br J Gen Pract. 2003;53(493):600-606.

41. Blenkinsopp A, Jepson M, Drury M. Using a notification card to improve communication between community pharmacists and general practitioners. Br J Gen Pract. 1991;41(344):116-118.

42. Tan EC, Stewart K, Elliott RA, George J. Integration of pharmacists into general practice clinics in Australia: the views of general practitioners and pharmacists. Int J Pharm Pract. 2014;22(1):28-37.

43. Nominal Fee: Time and knowledge should be compensated, says society chief. The New Straits Times 28 July, 2012. Available from: http:// www.mps.org.my/newsmaster.cfm?\&menuid=36\&action=view\&retr ieveid $=3655$. Accessed January 13, 2015.

44. Hargie O, Morrow N, Woodman C. Consumer perceptions of and attitudes to community pharmacy services. Pharmaceutical Journal. 1992;249:688-691. 
Patient Preference and Adherence

Dovepress

\section{Publish your work in this journal}

Patient Preference and Adherence is an international, peer-reviewed, open access journal that focuses on the growing importance of patient preference and adherence throughout the therapeutic continuum. Patient satisfaction, acceptability, quality of life, compliance, persistence and their role in developing new therapeutic modalities and compounds to optimize

Submit your manuscript here: http://www.dovepress.com/patient-preference-and-adherence-journa clinical outcomes for existing disease states are major areas of interest for the journal. This journal has been accepted for indexing on PubMed Central The manuscript management system is completely online and includes a very quick and fair peer-review system, which is all easy to use. Visit http://www. dovepress.com/testimonials.php to read real quotes from published authors. 